\title{
Tokyo Playground: The Interplay Between Infrastructure and Collective Space
}

\author{
Alice Covatta ${ }^{a}$
}

\begin{abstract}
Tokyo Playground aims to investigate the leftover space produced when the infrastructure overlaps with the urban tissue and to highlight how these are metabolized, then transformed into meaningful public spaces. The "hybridization" of Tokyo is examined using three references as a starting point. First is the spatial typology of sakariba that transformed what were transitional zones into pleasure districts during the Edo period, creating what was arguably the most definitive type of collective space for citizens of Edo. The second reference is Roland Barthes' description of the infrastructural experience. Thirdly, the book Made in Tokyo illustrated the strong mutual dependence among infrastructure, architecture, and the city as a unique characteristic of Tokyo. Transit space can be reused on the human scale with different programs related to time for pleasurable activities. Tokyo Playground aims to capture the idea of emotional space within infrastructure. It aims to highlight some possible design strategies and tools that help to domesticate the infrastructure through the injection of pleasure and playful programs with an understanding of how humans experience, occupy, and interpret such spaces. Leftovers within the infrastructure are opportunities for social and ecological reuse and these precious voids contribute to creating the contemporary soul of the city as it becomes the source of vibrant energy for transcultural urban regeneration.
\end{abstract}

\section{Keywords}

Infrastructure, recycle, leftover, sakariba, collective space

Every day, Tokyoites typically spend one hour commuting each way to and from home and work, which accumulates annually into a staggering 21 days spent commuting ${ }^{1}$. On average, free time available to Tokyoites after work is 2 hours 28 minutes while the average in Germany is 4 hours 15 minutes (Kowalczyk 2011). All but seven of the 20 busiest railway stations in the world are located in Tokyo ${ }^{2}$. Each day, an average of 3.64 million people pass through Shinjuku station ${ }^{3}$, making it by far the most crowded railway station in the world. These data give insight into the conditions of the second largest urban agglomeration in the world, covering a sprawling metropolitan area encompassing Tokyo,
Yokohama, Saitama, and Chiba that are home to more than 40 million people ${ }^{4}$.

On one hand, there is the massive metropolitan scale characterized by fast movement and mechanization that constitutes the hard apparatus essential for the urban economy. It can be described in terms of the "bigness", coined by Rem Koolhaas, in which identity coincides with dimension and quantity.

\footnotetext{
aKeio University, Japan

Correspondent Author:

Alice Covatta, $\Vdash 155-0032$ Tōkyō-to, Setagaya-ku, Daizawa, 2 Chome-19-7, Japan
} 
On the other hand, there is the soft dimension of the human beings who inhabit it, with their emotions, beliefs, and aspirations.

This paper aims to provide a picture of a possible design tool for answering the following question: How can design help merge these two seemingly opposing dimensions?

\section{TOKYO SUPER-INFRASTRUCTURE}

In contrast to other mega-cities, even those that have a comparatively dense population, the Tokyo Metropolitan Area is a paradigmatic case study defined by its uniquely extensive network of public transportation. The region has the highest average number of people using public transportation to commute to and from the outskirts, and in the Biennale of Venice in 2006, it was highlighted that $75 \%$ of residents use public transportation in Tokyo, while in London, the proportion is half (Burdett 2006).

The bigness of Tokyo, in terms of the flow of people and transportation systems conveying them, has resulted in a complex and idiosyncratic infrastructural network. This system forms the urban tissue into multiple layers: above ground, underground, commercial buildings, manufacturing facilities, retail complexes, residential areas, public spaces, etc.

Each urban element hybridizes its identity as it interacts with its surrounding infrastructure, resulting in what can be described as a "scrambled" landscape. The term "scrambled" is taken from an illustration titled "The City as an Egg" created by Cedric Price. The English architect, who often used food as a metaphor to illustrate architectural concepts, created a diagram of three eggs in 1982 as a schematic for the evolution of city planning. The first is the boiled egg, or the "walled city" in which the distinction between the yolk/center and the albumen/surroundings is well-defined by clear borders. Second, a fried egg represents the early modern formless expansion of the peripheral area but still retains its historically defined center. Finally, a diagram of a scrambled egg represents no clear distinction between yolk and albumen, and in which instead, everything is blended together. Tokyo, in Cedric Price's metaphor, is a scrambled egg for breakfast.

\section{TOKYO LEFTOVER FOR PLEASURE}

From a Japanese historical perspective, Tokyo's hybridization between infrastructure and collective space takes its roots from the typological form of sakariba, considered by some scholars as its precursor (Kowalczyk 2011). Sakariba was the term used to collectively refer to the entertainment and pleasure districts of the Edo period. Etymologically, the term derives from two words that clearly explain the essence of this place: sakaru, which means to be active, to be vigorous, and to flourish; and $b a$, meaning "place". Together, they make up the word sakariba, which is a catch-all term for settings that provide pleasure and amusement such as tea rooms, places of gathering for street artists, food stall districts in earlier periods; and bars, pachinko parlors, izakaya, and nightclubs in the present.

Spatially, the sakariba was defined as the busiest part of the city associated with pleasure and entertainment. It took form during the Edo period and henceforth grew spontaneously in open spaces and transitional zones because originally sakariba was the place of refuge in case of fire and the place of trade and shipping, then it later expanded around bridges (Kowalczyk 2011). Generally, they were located at a fair distance from residential areas and were closer to business districts, making them easily accessible after work for the masses. The spatial gap between work and home assumed an important cultural aspect in citizens' lives.

However, the temporal aspect of sakariba is what gives this spatial category its soul as the activities associated with it took place only in a precise interval of time between the Japanese concepts of hare and ke. 
The time of work and everyday commitments falls under $k e$ (profane) and in contrast, the time of prayer and rest falls under the category of hare (sacred). It is the gap in between work and rest which is devoted to pleasurable activities, such as socializing over glasses of sake in an izakaya establishment where work is temporarily forgotten or window-shopping on the way home. The most important aspect of this phenomenon that persists to this day is that the sakariba negates all social constraints and hierarchies, providing people with an almost utopian "classless capitalism" (Slater 2011) scenario.

\section{“TO COMMERCE, TO TRANSITION, TO DEPARTURE"}

The infrastructural network does not consist only in the flow of people. Instead, it is a sophisticated mechanism that functions on a multitude of scales and layers. When simplified, it is a combination of two main systems: one being the functional apparatus of infrastructural space composed by stations, railway lines, exits, escalators, elevators, etc., and its accompanying components are the collateral activities aimed at completing and augmenting the commuting experience such as shops, department stores, convenience stores, restaurants, bars, and other facilities that are associated with leisure and socializing. Both systems are deeply integrated into the urban tissue and citizens' lives.

While visiting Tokyo, the French philosopher Roland Barthes was impressed by the catalyzing power of its infrastructure and wrote of his experiences:

The station, a vast organism which houses big trains, the urban trains, the subway, a department store, and a whole underground commerce - the station gives the district this landmark which, according to certain urbanites, permits the city to signify, to be read. The Japanese station is crossed by a thousand functional trajectories, from the journey to the purchase, from garment to food: a train can open onto a shoe stall. Dedicated to commerce, to transition, to departure, and yet kept in a unique structure, the station (moreover, is that what this new complex should be called?) is stripped of that sacred character which ordinarily qualifies the major landmarks of our cities: cathedrals, town halls, historical monuments. (Barthes and Howard 2009)

Barthes rightly predicted the crucial role that infrastructure would play in forming the culture of this city. It is archetypal of Tokyo's DNA described in the typological research titled Made in Tokyo (Kaijima, Kuroda, and Tsukamoto 2012). The case studies presented therein highlighted Tokyoites' affinity with infrastructural beautification and recycling:

Traffic space has intruded into architecture in order to allow the execution of highly developed transportation system... The development of the logistic network has affected a huge change, and is one of the defining elements which have shaped the form of the city. Several of the building of made in Tokyo reflect this kind of change and beautifully condense the dynamism of this city.

\section{THREE CASES}

The sakariba concept functioned as an interval of space and time. It was a design example that shows how the transitional space compenetrates everyday life. Today, this interaction is still visible in different nuances within Tokyo's infrastructure as pointed out by Roland Barthes and recently by Yoshiharu Tsukamoto et al. The second part of this paper aims to highlight this interaction through three case studies.

The subjects of the case studies found in the centre of Tokyo are selected as they serve as examples of infrastructural recycling and hybridization within their given surroundings. These are Ameyoko market, Ichigaya Fish Center, and Shimokitazawa Cage.

What these have in common is that all are underneath railways where the interstitial void between the structure and the ground is occupied by different programs related to playfulness and pleasure. The leftovers found in between the infrastructural space become a new possibility of occupation and urban regeneration: an expression of the uncanny possibilities 
of void that can produce a unique landscape based on free time and pleasure (see Figure 1).

\section{CANDIES IN THE INFRASTRUCTURE: AMEYOKO}

Ueno is situated in an intermediate zone resulting from the mutual interaction between diverse urban typologies such as the residential districts of Taito Ward defined by low-rise housing; the legacy of eastern Tokyo's shitamachi culture; the historical/touristic landmarks of Asakusa and Ueno Park; and the modern commercial district of Akihabara.

The scrambled nature of this urban landscape also mirrors the diversity of social groups that mix in the narrow shopping streets and shotengai around Ueno Station which was, in the pre- to post-war period the first point of entry into Tokyo for those arriving from the north of Japan for employment and education. It is to this day a major transit hub on both the city and regional scales with a direct railway link with Narita Airport as well as being an anchor-point in the circular Yamanote Line.

In this environment, global and local scales are seamlessly integrated. The elevated railway houses countless shops, eateries, and bars beneath it and is an integral part of the Ameyoko market which emerged after WWII. Ameyoko is an abbreviation of the words, ameya yokocho meaning "candy alley" firstly because candy was historically sold here and secondly because after WWII, this was the location for black market stalls where products originally from the US were traded which led to the word ame taking on the meaning of "America".

Today, no one really knows exactly how many vendors operate in the district and it seems to be one of the last places in Japan where bargaining a price is recognized. The market stretches along a segment spanning 400 metres underneath the railway. Since its beginnings approximately 70 years ago, the establishments have continuously evolved, adding new design features to enhance their commercial performance. Some of these are discussed as follows.

The existing infrastructure defines the dimensions of retail establishments by factors such as the width of pillars and ceiling height. Lights, neon signs, canopies, and air conditioning units hang haphazardly over the shops. Often, there is a small platform that extends from the shop, slightly raised from ground level, which serves as a clearly defined division from the street. The actual trading takes place in the border of the shops' thresholds. In fact, vendors typically conduct their trade in the exterior portion of their shops, as if they were operating an outdoor stall.

Vendors and customers interact with one another on this border, each trying to get the best deal of the day.

Aesthetics is not a priority, as almost all available spaces are filled with products and tools of the trade to maximize profitability.

Ameyoko sets an example for maximizing the reuse of leftover space. Firstly, on the small scale, each interstice assumes a consumeristic uniqueness that is driven by constant design adaptation. Secondly on the larger scale, the market extends its influence to the buildings and narrows streets surrounding it.

The economical benefits define how the infrastructure is occupied.

\section{SHIMOKITAZAWA CAGE}

Shimokitazawa Cage, operated by Keio Corporation, consists of a pop-up space for street food trucks, a multipurpose event space called the "Cage", and a parking lot underneath the Keio railway line which is currently still undergoing construction. The project was built in 2016 and is set to be open until 2019 when the new railway line will begin operating. During the railway's construction, there were various conflicts with the locals. 
The Cage had to be built in such a way that it does not come in contact with the infrastructural frame, so the entire structure is made up of an assemblage of modular component that allows the interior to be altered in accordance with the program being held inside. The Cage has been designed by Speac Architect to accommodate a diverse mixture of functions: some of them are periodical like markets, film events, theatrical performances, and talk shows. Others are on a one-off basis in which the space is rented according to availability, such as the promotion of tobacco products or private parties. There are also times when the Cage is simply open to the public as a "chilling space", with no prescribed purpose.

Each program needs specific configurations and custom design solutions. One key feature for audiovisual functions, such as film screenings, theatrical performances, and talk events, is the wireless headsets which allow for the creation of a "sound bubble", isolating noise within the Cage so that audio is limited to the participants within and does not affect nearby residents and passersby.

Its example highlights the effectiveness of using leftover space in a way that helps local citizens gradually accept the transformation of their urban environment from the familiar to the new.

\section{CARPS IN THE INFRASTRUCTURE: ICHIGAYA FISH POND}

Ichigaya Fish Center is located on Kanda River at the crossing by Ichigaya Station where Yasukuni Street and Sotobori Street intersect at Ichigaya Bridge. It is adjacent to the railway tracks of the Chuo Main Line, at one of the comparatively busier road and railway hubs in central Tokyo. In contrast to most other waterscapes in Tokyo, i.e. rivers, bay area, and the moat surrounding the Imperial Palace, here the waterway is not used for the purposes of industry, sewage, or defence. Rather, it has been formed into ponds for recreational fishing, creating a unique space where people can enjoy this outdoor activity while being in the centre of Tokyo.

The connection between the fishing centre and the infrastructure is both topographical and visual in the sense that they create a heterogeneous landscape with a shared topographical section: with the railway station situated on the top, followed by a bank full of cherry trees, and at the fishing centre located at the bottom.

No visual barriers exist between these different elements, and the topography enables a coincidental and almost voyeuristic interaction to take place: Waiting passengers at Ichigaya Station watch the people at the pond trying to catch fish, while they in turn provide the unusual backdrop for the anglers as they patiently wait for a carp to take the bait.

This interstitial playground is a popular spot attracting a heterogeneous mix of clientele: suited "salarymen" passing time during a lunch break, families with children, fishing enthusiasts, young couples, etc.

Although, the fishing centre is by no means an example of sophisticated urban design, it offers a uniquely juxtaposed view of the city to its clientele. This hybrid context allows the mind to wander in new ways amongst the bigness of the city.

\section{CONCLUSIONS}

Tokyo's bigness is perpetual because part of the city will always be dedicated to large-scale commerce and industry. However, when the two opposite dimensions of infrastructural bigness and the smallness of human activities are in mutual inclusion rather than exclusion, the leftover spaces become opportunities for social reaction and urban regeneration. Through the analysis of the case studies and theoretical references, some urban strategies emerged to enable spatial inclusion and give a soul to these residual spaces which would otherwise simply be inactive. Four aspects of this phenomenon are presented as follows. 

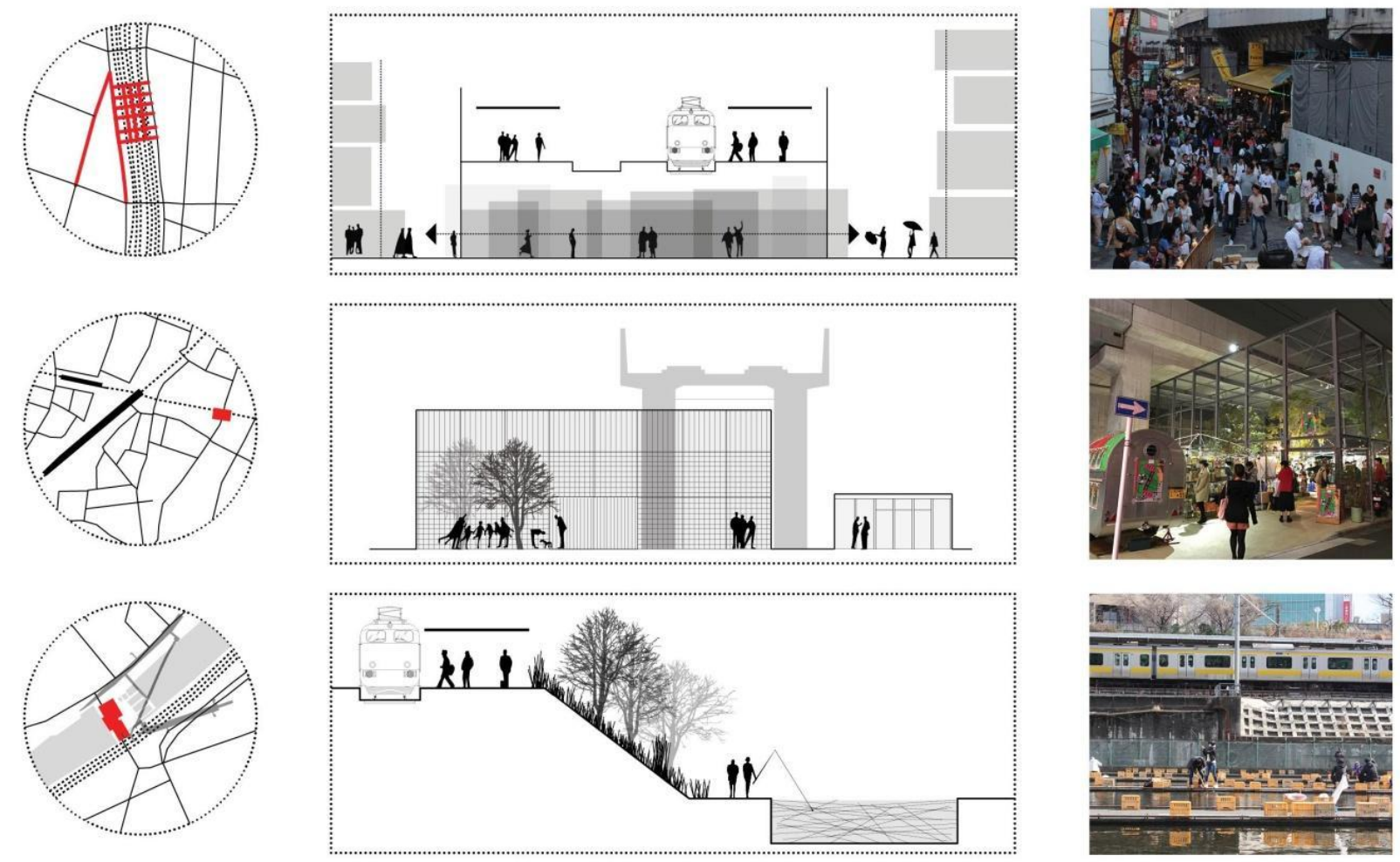

Figure 1. The Three Case Studies: Ameyoko, Shimokitazawa Cage, and Ichigaya Fish Pond.

"Mirror". The leftover space is a way of expression of the urban surroundings as a manifestation and accumulation of contrasting experiences. Therefore, it is a tool that is not only related to the infrastructural context but also highlights the complex dynamics of the human experience within the city.

"Openness" of time and space as exemplified by the sakariba. If urban regeneration aims to initiate the redevelopment of infrastructure, the new project needs to be designed in a way that addresses both space and time, taking into consideration the spatial accessibility to and from the surroundings and the diverse possibilities for activities in which people can engage in their free time.

"Pleasure". Upon completion, the bigness of an infrastructure induces a kind of stasis in its surroundings by virtue of its relative permanence. However, on the small scale of human activities, the stability and perceived permanence of bigness is mitigated by the ephemeral nature of pleasurable activities ${ }^{5}$.

"Recycling". In Tokyo, the recycling of infrastructure has been a long-standing practice that comes hand in hand with a lifestyle defined by the city's extensive railway network. Although the phenomenon initially emerged in the form of bottom-up appropriation of space as exemplified by Ameyoko and Ichigaya, today, the driving force has been replaced by a top-down approach, i.e. initiated by major developers, government entities, and other comparable organisations. The JR East Urban Development Corporation is redesigning many "leftover" spaces underneath the rails ${ }^{6}$ to improve the 
consumption experience for different social groups. If the recycling of the infrastructure shapes the city of tomorrow, then retail complexes would be the most common end result of such recycling.

\section{Acknowledgements}

The author is grateful for research support from the Japan Foundation and their Fellowship for Intellectual Exchange. Some of the ideas of this paper have been explored with the help and inspiration of Colabo Laboratory of Urban Design at Keio University.

\section{Notes}

1. Tokyo Salary-Men Spend 20 Days a Year for Commuting. 2010. Retrieved May 24, 2017 (http://www.japanstyle.info/ 09/entry8884.html).

2. The 51 Busiest Train Stations in the World-All but 6 Located in Japan. 2013. Retrieved May 28, 2017 (https://japantoday.com/category/features/travel/the-51-busi est-train-stations-in-the-world-all-but-6-located-in-japan).

3. The World's Busiest Train Stations. N.d. Retrieved May 22, 2017 (http://www.railway-technology.com/features/feature worlds-busiest-train-stations).

4. Major Agglomerations of the World-Statistics and Charts in Maps, Diagrams and Tables. N.d. Retrieved May 31, 2017 (https://citypopulation.de/world/Agglomerations. html).

5. In different cultural contexts, the abandoned infrastructural landscape changes use classification and gives birth to park and new public space that happened for example to the trendy New York's High Line linear park or its predecessor the Promenade Plantée in Paris or the latest recently inaugurated Seoullo 7017 designed by MVRDV. All are design operation followed by a large mediatic circulation on the local and global scale.

6. For a better overview about the Developer JR East Urban Development of JR East group's projects, see (http://www.jrtk.jp.e.wz.hp.transer.com/).

\section{References}

Barthes, R. and R. Howard. 2009. Empire of Signs. New York,
NY: Hill and Wang.

Bauman, Z. 2003. Wasted Lives: Modernity and Its Outcasts. Cambridge: Polity Press.

Bestor, V. L., T. C. Bestor, and A. Yamagata. 2013. Routledge Handbook of Japanese Culture and Society. Abingdon, Oxon: Routledge.

Boontharm, D. and D. Radović. 2012. Small Tokyo. Tokyo: Flick Studio.

Burdett, R. 2006. Cities, Architecture and Society: La Biennale di Venezia; 10th International Architecture Exhibition. Milano: Marsilio Ed.

Hidenobu, J. 2011. Tokyo: A Spatial Anthropology. Berkeley: University of California Press.

Isozaki, A. and D. B. Stewart. 2011. Japan-ness in Architecture. Cambridge, MA: MIT.

Kaijima, M., J. Kuroda, and Y. Tsukamoto. 2012. Made in Tokyo. Tokyo: Kajima Inst. Publ.

Koolhaas, R. and B. Mau. 1998. S, M, L, XL. New York: Monacelli Press.

Koolhaas, R. and H. Foster. 2013. Junkspace With Running Room. London: Notting Hill Editions.

Kowalczyk, B. M. 2011. "Invisible (Tokyo Station) City of Transformation: Social Change and Its Spatial Expression in Modern Japan." Asian and African Studies 15(3):23-38.

Slater, D. H. 2011. "Social Class and Identity in Postwar Japan." Pp. 103-116 in Routledge Handbook of Japanese Culture and Society, edited by V. L. Bestor, T. C. Bestor, and A. Yamagata. New York and Oxford: Routledge.

Zacharias, J., T. Zhang, and N. Nakajima. 2011. "Tokyo Station City: The Railway Station as Urban Place." URBAN DESIGN International 16(4):242-251.

\section{Bio}

Alice Covatta, architect, researcher, and illustrator, she achieved bachelor and master's degrees in Architecture with honor at IUAV University of Venice. Later she worked as architect in Italy and Spain dealing with architectural and landscape projects. She received her Ph.D. in Architecture from University of Udine with one-academic year at Keio University in Tokyo. Nowadays, Alice is PostDoc research fellow in Architecture and Urban Design at Keio University granted by Japan Foundation Fellowship. Her works have been exposed at MAXXI Museum in Rome, Toronto University, Venice Biennale, and LoopHole in Melbourne; research fields: architecture and urban design. 